\title{
Assessment of Contractility for Fontan Connections
}

\author{
Mert Kestelli ${ }^{1}$, Sahin Bozok ${ }^{2 *}$ \\ ${ }^{1}$ Department of Cardiovascular Surgery, Izmir Ataturk Training and Research Hospital, Izmir, Turkey \\ ${ }^{2}$ Department of Cardiovascular Surgery, Faculty of Medicine, Recep Tayyip Erdoğan University, Rize Training \\ and Research Hospital, Rize, Turkey \\ Email: sahinboz@yahoo.com
}

Received 6 February 2014; revised 6 March 2014; accepted 14 March 2014

Copyright (C) 2014 by authors and Scientific Research Publishing Inc.

This work is licensed under the Creative Commons Attribution International License (CC BY).

http://creativecommons.org/licenses/by/4.0/

(c) (i) Open Access

\section{Abstract}

This study is performed to investigate the effect of Fontan operations on cardiac contractility. Investigation of articles about the contractility in Fontan published in PubMed up to now revealed that the measurement of contractility values did not include the rudimentary ventricle. Connections between right atrium and right ventricle as well as right atrium and pulmonary artery were studied in the same group as well. In our opinion, for the single ventricular physiology, the RA-RV and RA-PA connected patients' preload and afterload values cannot be calculated in the same group since volume of rudimentary ventricles must be considered from this point of view as well.

\section{Keywords}

Myocardial Contractility, Fontan Procedure, Rudimentary Ventricle, Tricuspid Atresia, Double Inlet Ventricle

\section{Introduction}

Complete bypass of the right ventricle was initially performed successfully and subsequently reported by Fontan and Baudet for patients with tricuspid atresia. Elimination of the congenital and surgical shunts allowed the avoidance of ventricular volume overload and pulmonary hypertension. The Fontan operation, one of the historic advances in the surgical treatment of congenital heart disease, has great application to patients with various forms of univentricular heart. The procedure, bearing Fontan's name, transfers the whole vena cava blood to the lungs in a setting where only oxygenated blood returns to the left heart. In this way, the right atrium was "ventriclized". Importantly, it is only applied to well developed children with pulmonary arteries "large enough and

${ }^{*}$ Corresponding author. 
at sufficiently low pressure to allow a cava-pulmonary anastomosis”. This procedure is named to be a physiological correction that suppressed shunting and avoided such hazards of systemic artery to pulmonary artery shunts as pulmonary hypertension, rather than being an anatomical correction, which would have required creation of a right ventricle [1]. For non-disturbed ventricles in circumstances such as tricuspid atresia and double inlet ventricle, ejection fraction starts to diminish after 5 years of age due to the cyanosis and volume overload [2].

This paper analyses the methodology utilized to evaluate contractility and hemodynamics after Fontan procedure in the literature up to now. Our suggestions for obtaining more accurate results from the analysis of cardiac parameters after Fontan procedure including Fontan-Bjoerk [right atrium (RA)-right ventricle (RV)], and Fontan-Kreutzner [RA-pulmonary artery (PA)] along with a review of literature are presented. The articles published in PubMed about the contractility in Fontan operations were investigated in terms of assessment of contractility. Analyses of parameters that are considered for the evaluation of contractility along with our recommendations for a more accurate assessment are presented in this paper. Accurate analysis of parameters contributing to circulation after Fontan procedure may help to understand and eliminate the factors affecting mortality (due to cardiac failure) and morbidity (due to the postoperative reduction in EF and inappropriate hypertrophy) after Fontan procedure.

\section{Materials and Method}

In congenital disorders sparing the ventricle such as tricuspid atresia and double inlet ventricle, assessment of patients must be made separately for RA-RV and RA-PV connections in Fontan Procedure. Contribution of rudimentary ventricle to hemodynamics and circulation must not be ignored for a healthy evaluation in order to achieve a better diagnostic view and better therapeutic outcomes.

In the literature, methodology for assessment of contractility after Fontan procedure is not uniform and involves some debatable points: Mostly, RA-RV and RA-PA connections were evaluated within the same group [2]-[5]. Only, Rhodes had grouped the patients with respect to RA-RV and RA-PA connections, but in this study the cardiac outputs had not been compared separately [6], either. This could result a misinterpretation of results.

Rudimentary ventricle is usually ignored during the evaluation of ventricular parameters [2]-[5] [7]-[9]. The location and morphology of the rudimentary ventricles correlate with the disposition of the atrioventricular conduction system. Therefore, more accurate results can be obtained if rudimentary ventricles are taken into account.

Measurement of contractility in univentricular hearts have been based on the main ventricle solely. Left ventricle (LV) measurements were made by using anteroposterior measurement of mitral valve and LV semiminor axis has been considered during measuring the velocity of circumferential fiber shortening (VCFc) (Graham). Ejection fraction (EF) measurements are usually done by utilizing LVEF only [4] [7] [8] [10]-[12].

\section{Discussion}

In Fontan operations, underdeveloped right ventricle is excluded from circulation. Thus, blood goes to the lungs passively from the systemic venous return. Hence, the pulmonary arteries should be well developed and pressure in pulmonary circulation should be lower than systemic venous return [13].

In our opinion, unless the volume of the rudimentary ventricle is considered, preload and afterload values in patients with RA-RV and RA-PA connections cannot be calculated healthily within the same group.

In order to provide the clinician with more sophisticated diagnostic techniques, a better understanding of the mechanics and performance of the myocardium is necessary. This calls for an accurate analysis of the forces and stresses occurring in the wall of the left ventricle during the cardiac cycle. In calculation of the wall forces for the left ventricle, the law of Laplace, which relates the pressure difference across a membrane surface to its curvature and surface tension, can be applied [14].

Observations of hearts in humans suggested that heart mass is proportional to body weight. Heart mass and radius are also closely related. An increase in radius leads to an increase in mass to preserve the normal relationship. When the radius increases without commensurate changes in mass, compensatory mechanisms exist that lead to further dilatation and, eventually to heart failure. In the Law of Laplace, being used in the context of cardiovascular physiology, arteries may be viewed as cylinders, and the left ventricle can be viewed as part cylinder. The Law of Laplace can be summarized as $\mathrm{T}=\mathrm{p} \times \mathrm{r} /(2 \times \mathrm{t})$, where $\mathrm{T}$ stands for wall tension, $\mathrm{p}$ stands 
for pressure, $\mathrm{r}$ symbolizes radius, and t symbolizes wall thickness. For a given pressure, increased radius requires an increased wall thickness to accommodate a stable wall tension. Increased pressure requires increased thickness to maintain a stable wall tension. The latter is used to explain the thickening of arteries and thickening of the left ventricle to accommodate high blood pressure. However, the thickened left ventricle is stiffer when the thickness is normal, so it requires elevated pressures to fill, a condition known as diastolic heart failure. Thus, an increase in the radius leads to increased wall tension and increased myocardial oxygen consumption. Theoretically, there are three ways to reverse this situation: 1) increase the LV mass (this is impossible for the time being but may constitute the basis for cardiomyoplasty); 2) diminish the wall tension by medical therapy (vasodilators); or 3) reduce the radius of LV (cardioreduction) [14].

Hypoplastic ventricles, either normally constituted or rudimentary or incomplete, possess smaller cavities than expected. The reduced size of the cavity can be produced as a consequence of hypertrophy of overgrowth of the ventricular wall. Definitive rules remain to be established in order to precisely quantitate the role of a rudimentary ventricle in the systemic or the pulmonary circulation [14].

Whenever the diameter and the wall thickness of the rudimentary ventricle are excluded from the ventricular stress formulae derived from Laplace rule, acquisition of the correct ventricular stress results is impossible. This would interfere with the correct interpretation of the causes of the mortality and morbidity in a single ventricle.

We suggest that in the single ventricle, the volume and diameter calculations must include rudimentary ventricle due to the Laplace rule as explained above [15]. In case rudimentary ventricle is not included, the contractility measurements such as ejection fraction of the main ventricle, fractional shortening of the lone systemic ventricle and only velocity circumferential meridional shortening would be incorrect.

To perform a thorough evaluation of the contractility after the right heart bypass operations, the contribution of rudimentary ventricle must be kept in mind.

\section{References}

[1] Cowgill, L.D. (1991) The Fontan Procedure: A Historical Review. The Annals of Thoracic Surgery, 51, $1026-1030$. http://dx.doi.org/10.1016/0003-4975(91)91044-V

[2] Akagi, T., Benson, L.N., Willams, W.G. and Freedom, R.M. (1993) Regional Ventricular Wall Motion Abnormalities in Tricuspid Atresia after the Fontan Operation. Journal of the American College of Cardiology, 22, 1182-1188. http://dx.doi.org/10.1016/0735-1097(93)90435-4

[3] Chin, A.J., Franklin, W.H., Andrews, B.A. and Norwood, W.I. (1993) Changes in Ventricular Geometry Early after Fontan Operation. The Annals of Thoracic Surgery, 56, 1359-1365. http://dx.doi.org/10.1016/0003-4975(93)90682-8

[4] Seliem, M., Muster, A.J., Paul, H.M. and Benson, D.W. (1989) Relation between Preoperative Left Ventricular Muscle Mass and Outcome of the Fontan Procedure in Patients with Tricuspid Atresia. Journal of the American College of Cardiology, 14, 750-755. http://dx.doi.org/10.1016/0735-1097(89)90121-6

[5] Graham, T.P., Franklin Jr., R.C., Wyse, R.K., Gooch, V. and Deanfield, J.E. (1986) Left Ventricular Wall Stress and Contractile Function in Childhood: Normal Values and Comparison of Fontan Repair versus Palliation Only in Patients with Tricuspid Atresia. Circulation, 74, I61-I69.

[6] Rhodes, J., Garofano, R.P., Bowman, F.O., Grant, G.P., Bierman, F.Z. and Gersony, W.M. (1990) Effect of Right Ventricular Anatomy on the Cardiopulmonary Response to Exercise. Circulation, 81, 1811-1817. http://dx.doi.org/10.1161/01.CIR.81.6.1811

[7] Gewillig, M.H., Lundström, U.R., Deanfield, J.E., Bull, C., Franklin, C.R., Graham, P.T., et al. (1990) Impact of Fontan Operation on the Left Ventricular Size and Contractility in Tricuspid Atresia. Circulation, 81, 118-127. http://dx.doi.org/10.1161/01.CIR.81.1.118

[8] Sluysmans, T., Sanders, S.P., vander Velde, M., Matitiau, A., Parness, I.A., Spevak, P.J., et al. (1992) Natural History and Patterns of Recovery of Contractile Function in Single Left Ventricle after Fontan Operation. Circulation, 86, 1753-1761. http://dx.doi.org/10.1161/01.CIR.86.6.1753

[9] Kouatli, A.A., Garcia, J.A., Zellers, T.M., Weinstein, E.M. and Mahony, L. (1997) Enalapril Does Not Enhance Exercise Capacity in Patients after Fontan Procedure. Circulation, 96, 1507-1512. http://dx.doi.org/10.1161/01.CIR.96.5.1507

[10] Sandor, G.G., Patterson, M.W. and LeBlanc, J.G. (1994) Systolic and Diastolic Function in Tricuspid Valve Atresia before the Fontan Operation. The American Journal of Cardiology, 73, 292-297. http://dx.doi.org/10.1016/0002-9149(94)90236-4

[11] Sano, T., Ogawa, M., Taniguchi, K., Matsuda, H., Nakajima, T., Arisawa, J., et al. (1989) Assessment of Ventricular 
Contractile State and Function in Patients with Univentricular Heart. Circulation, 79, 1247-1256. http://dx.doi.org/10.1161/01.CIR.79.6.1247

[12] Weipert, J., Koch, W., Haehnel, J.C. and Meisner, H. (1997) Exercise Capacity and Mid-Term Survival in Patients with Tricuspid Atresia and Complex Congenital Cardiac Malformations after Modified Fontan-Operation. European Journal of Cardio-Thoracic Surgery, 12, 574-580. http://dx.doi.org/10.1016/S1010-7940(97)00220-0

[13] Giroud, J.M. and Jacobs, J.P. (2006) Fontan’s Operation: Evolution from a Procedure to a Process. Cardiology in the Young, 16, 67-71. http://dx.doi.org/10.1017/S1047951105002350

[14] Batista, R.J., Verde, J., Nery, P., Bocchino, L., Takeshita, N., Bhayana, J.N., et al. (1997) Partial Left Ventriculectomy to Treat End-Stage Heart Disease. The Annals of Thoracic Surgery, 64, 634-638. http://dx.doi.org/10.1016/S0003-4975(97)00779-0

[15] Kestelli, M., Emrecan, B., Lafci, B., Ozsoyler, I., Yilik, L., Ozbek, C., et al. (2006) A Pulmonary Ventricle System Producing Pulsatile Pressure in Single Ventricle: Experimental Model. Brazilian Journal of Cardiovascular Surgery, 21, 324-327. http://dx.doi.org/10.1590/S0102-76382006000300012 